\title{
UPAYA MENINGKATKAN HASIL BELAJAR BAHASA INDONESIA PADA KOMPETENSI MENENTUKAN KOSA KATA TENTANG PERISTIWA SIANG DAN MALAM DENGAN MENGGUNAKAN MODEL PEMBELAJARAN EXAMPLE NON-EXAMPLE PADA SISWA KELAS I SDN BERANGAS 1 KECAMATAN ALALAK
}

\author{
Marliana Noor \\ Email: marliananoor1975@gmail.com \\ Sekolah Dasar Negeri Berangas 1 Barito Kuala
}

\begin{abstract}
In the process of teaching and learning, there is often one direction of learning, the learning media are not appropriate and then no variety of learningmethods, causing a lack of student interest in learning and low completeness of learning outcomes. This research has been conducted using the example non example learning method in two cycles, each cycle is divided into two meetings with the percentage of teacher and student activity scores. The results showed that in the first cycle of the first meeting, the score of teacher and student activity respectively obtained $66.7 \%$ with a fairly good category and $63.6 \%$ of students being active. At the second meeting, the results obtained were $70.8 \%$ in the good category and $68.2 \%$ of the students were active. In the second cycle, there was an increase in the score compared to the first cycle, the second cycle of the first meeting had an increase of $77.1 \%$ in the very good category and $75 \%$ of the students were active. At the second meeting it reached $85.4 \%$ in the very good category and $81.8 \%$ of students were active. The results showed that the method used was very effective in increasing student activity and improving Indonesian learning outcomes on the competence of determining vocabulary about day and night events.
\end{abstract}

Keywords: Learning Outcomes, Indonesian Language, Learning Cycle, Example NonExample

\section{PENDAHULUAN}

Upaya pendidikan tersebut seringkali terkendala karena kebiasaan guru memonopoli pembelajaran, tidak menggunakan media yang tepat, metode yang digunakan tidak bervariasi, lebih banyak menggunakan metode ceramah, sehingga siswa kurang termotivasi untuk belajar dan membosankan. Hal tersebut berakibat pada siswa menjadi tidak focus dalam mengikuti pembelajaran dan kurang mengusai kompetensi secara optimal, siswa kurang aktif secara langsung dalam mengikuti pembelajaran.

Data menunjukkan bahwa rendahnya hasil belajar belajar siswa mata pelajaran Bahasa Indonesia, khususnya kompetensi menentukan kosa kata tentang peristiwa siang dan malam, dari 18 orang siswa hanya 8 orang atau 44,4\% yang mampu mencapai KKM, 
sedangkan 12 orang siswa atau 66,6\% belum berhasil mencapai KKM. Setiap guru pada kegiatan pembelajaran di kelas pasti menginginkan siswanya antusias memperhatikan penjelasan guru, tanggap terhadap umpan balik yang diberikan guru dan dapat mencapai hasil belajar tuntas, tetapi kenyataannya masih banyak siswa yang kurang memperhatikan penjelasan guru, kurang merespon/menanggapi umpan balik yang diberikan guru, serta belum bisa menyelesaikan tugas yang diberikan oleh guru dengan baik sehingga daya serap siswa masih belum memenuhi standar KKM Kompetensi Dasar yang sudah ditetapkan yaitu 70.

Berdasarkan permasalahan ini, prioritas pemecahan masalah yang akan digunakan yaitu menggunakan model pembelajaran example non example, proses pembelajaran akan melibatkan siswa untuk meningkatkan keaktifan dimana siswa dapat melihat contoh dan dapat menganalisis gambar serta mampu meningkatkan hasil belajar siswa.

\section{TINJAUAN TEORITIS}

\section{Belajar dan Pembelajaran}

Menurut Elliott (Abimanyu, 2008) "Belajar dapat terjadi apabila ada stimulus dan respon". Artinya belajar merupakan salah satu jenis perilaku (behavior) indvidu atau peserta didik yang dilakukan secara sadar, indvidu Belajar adalah suatu proses mental dan emosional atau proses berfikir dan merasakan. Seseorang dikatakan belajar jika fikiran dan perasaannya aktif sehingga semakin tepat dan intensif kegiatan belajar yang dilakukan peserta didik.

\section{Konsep Dasar Model Pembelajaran}

\section{Model Pembelajaran}

Model pembelajaran adalah seluruh rangkaian penyajian materi ajar yang meliputi segala aspek sebelum,sedang dan sesudah pembelajaran dilakukan guru serta segala fasilitas yang terkait yang digunakan secara langsung atau tidak langsungdalam proses belajar mengajar Model pembelajaran dapat diartikan sebagai suatu rencana atau pola yang digunakan dalam menyusun kurikulum, mengatur materi peserta didik, dan member petunjuk kepada pengajar di kelas dalam setting pembelajaran. Istilah model pembelajaran mempunyai makna yang lebih luas daripada strategi, metode, atau prosedur. Model pembelajaran mempunyai 4 cirikhusus yang tidakdimiliki oleh strategi, metode, atau prosedur.

Ciri- ciri tersebut antara lain:

a. Rasional teoritik yang logis, disusun oleh para pencipta atau pengembangnya. 
b. Landasan pemikiran tentang apa dan bagaimana siswa belajar (tujuan pembelajaran yang akan dicapai)

c. Tingkah laku mengajar yang diperlukan agar model tersebut dapat dilaksanakan dengan berhasil

d. Lingkungan belajar yang diperlukan agar tujuan pembelajaran itu dapat tercapai

\section{Model Pembelajaran Example non example}

Example and Non example adalah model yang dapat digunakan untuk mengajarkan definisi konsep. Konsep ini bertujuan untuk mempersiapkan siswa secara cepat dengan menggunakan dua hal yang terdiri dari example dan non-example dari suatu definisi konsep yang ada, dan meminta siswa untuk mengklasifikasikan keduanya sesuai dengan konsep yang ada. Example memberikan gambaran akan sesuatu yang menjadi contoh akan suatu materi yang sedang dibahas, sedangkan nonexample memberikan gambaran akan sesuatu yang bukanlah contoh dari suatu materi yang sedang dibahas(http://biologyeducationresearch.blogspot.com).

Taktik yang dimaksud di sini memiliki tujuan untuk mempermudah para siswa dengan cepat dalam memahami suatu definisi konsep yang hendak diajarkan guru kepada siswa dengan cara meminta siswa untuk melakukan klasifikasi atau penggolongan dari example maupun non example. Example member sebuah gambaran dari sesuatu yang menjadi contoh sesuai materi yang sedang dibahas, sedangkan non example member sebuah gambaran terhadap sesuatu yang bukan merupakan contoh dari materi yang dibahas.

Menurut Roestiyah (2001) examplenon example didefinisikan sebagai model pembelajaran yang mempersiapkan dan menggunakan gambar atau diagram maupun tabel yang telah disesuaikan dengan materi ajar dan kompetensi dasar,

Adapun penyalinan gambar dapat berupa gambar temple atau menggunakan LCD proyektor.

Langkah- langkah dalam model pembelajaran Example non example

Model pembelajaran example non example sesuai dengan pendapat Agus Supriyono (2009) dapat dilakukan dengan 7 langkah, yaitu: 
a. Guru mempersiapkan berbagai gambar yang disesuaikan dengan tujuan pembelajaran. Berbagai gambar yang dipakai haruslah relevan dengan materi ajar yang akan dibahas guru.

b. Guru menyajikan atau menampilkan gambar dengan cara menempelkan gambargambar tersebut di papan tulis.

c. Guru memberikan arahan dan kesempatan kepada siswa untuk mengamati dan menganalisa gambar- gambar yang telah disajikan.

d. Siswa mencatat hasil analisa dari gambar setelah melakukan diskusi kelompok yang terdiri dari 2-3 siswa. Hasil analisa sebaiknya dicatat dikertas yang disediakan guru.

e. Tiap kelompok diberi kesempatan untuk membacakan hasil diskusinya.

f. Mulai dari komentar ataupun hasil diskusi siswa, guru mulai menjelaskan materi sesuai dengan tujuan yang ingin dicapai.

g. Guru bersama- sama siswa menyimpulkan materi sesuai dengan tujuan pembelajaran.

\section{METODE PENELITIAN}

Penelitian ini menggunakan pendekatan deskritptif kualitatif yaitu menggambarkan secara objektif dan actual tahapan proses pembelajaran di kelas. Jenis penelitian yang digunakan adalah tindakan kelas (Classroom Action Research). Langkah dan tahapan dalam penelitian ini yaitu:

1. Perencanaan, yaitu mengembangkan rencana tindakan dalam pembelajaran.

2. Tindakan, yaitu bertindak untuk melaksanakan rencana tersebut.

3. Observasi, yaitu pengamatan efek tindakan tersebut dalam konteks penelitiannya.

4. Refleksi, yaitu merefleksikan efek sebagai dasar bagi perencanaan lanjutan atau melalui tahapan.

Tahapan Pelaksanaan tindakan kelas tersebut dapat digambarkan pada bagan berikut: 


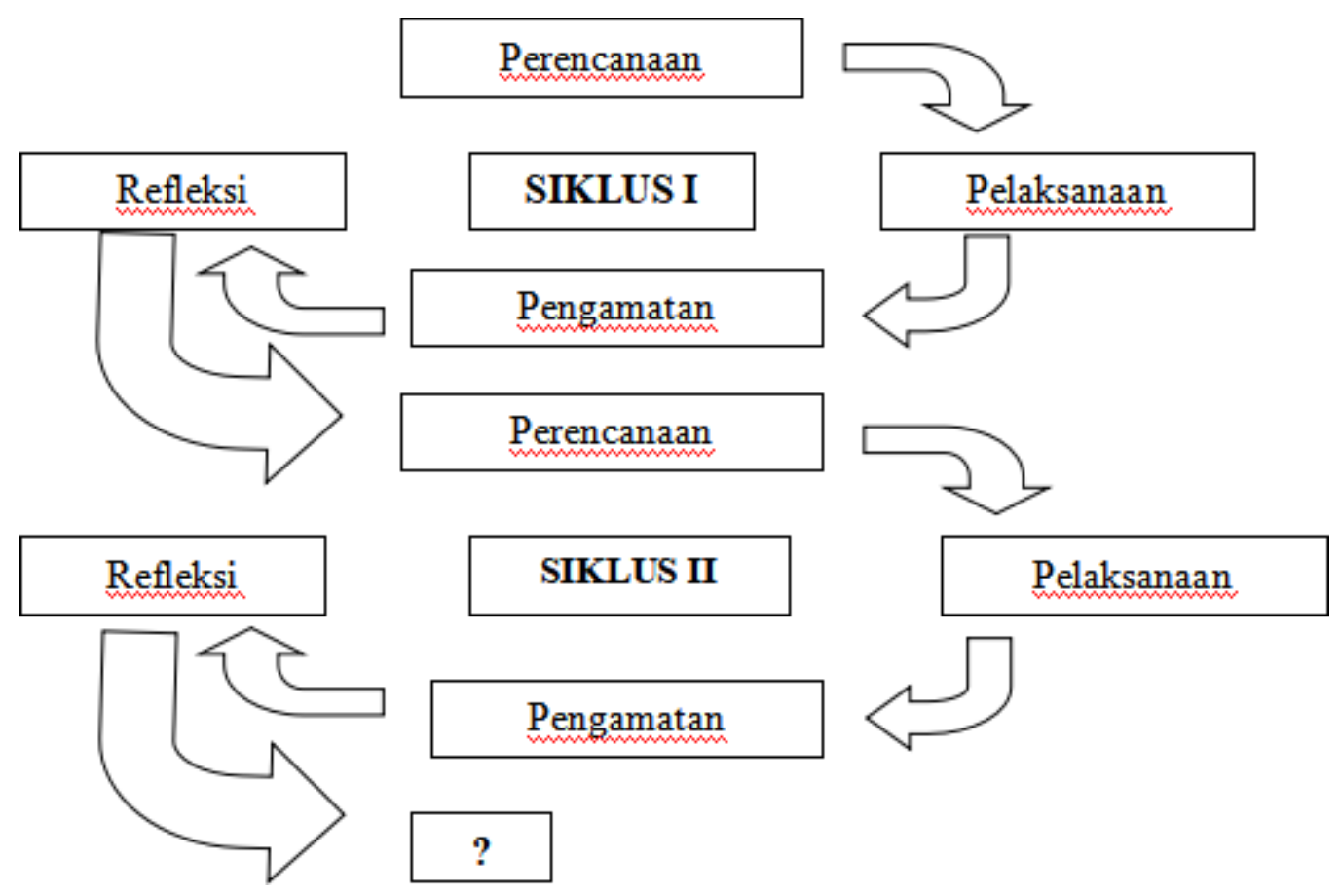

\section{HASIL PENELITIAN DAN PEMBAHASAN}

\section{Aktivitas Guru}

Berdasarkan hasil observasi siklus I pertemuan 1 aktivitas guru memperoleh skor 32 atau mencapai 66,7\% dengan kategori cukup baik pertemuan 2 memperoleh 34 atau 70,8\% dengan kategori baik. Kecendrungan kenaikan terus terjadi di setiap pertemuannya siklus II pertemuan 1 mengalami peningkatan skor menjadi 37 atau 77,1\% dengan kategori sangat baik, hingga pertemuan 2 mencapai skor 41 atau 85,4 \% dengan kategori sangat baik. Hal ini mengidentifikasi bahwa aktivitas guru di setiap pertemuannya harus mengalami perbaikan sehingga proses pembelajarannya terlaksana sesuai dengan langkah-langkah pembelajaran yang telah direncanakan. Kecenderungan aktivitas guru dari siklus I pertemuan 1 sampai pertemuan 2 dan siklus II pertemuan 1 sampai pertemuan 2 terjadi peningkatan sebagai mana terlihat pada grafik berikut ini. 


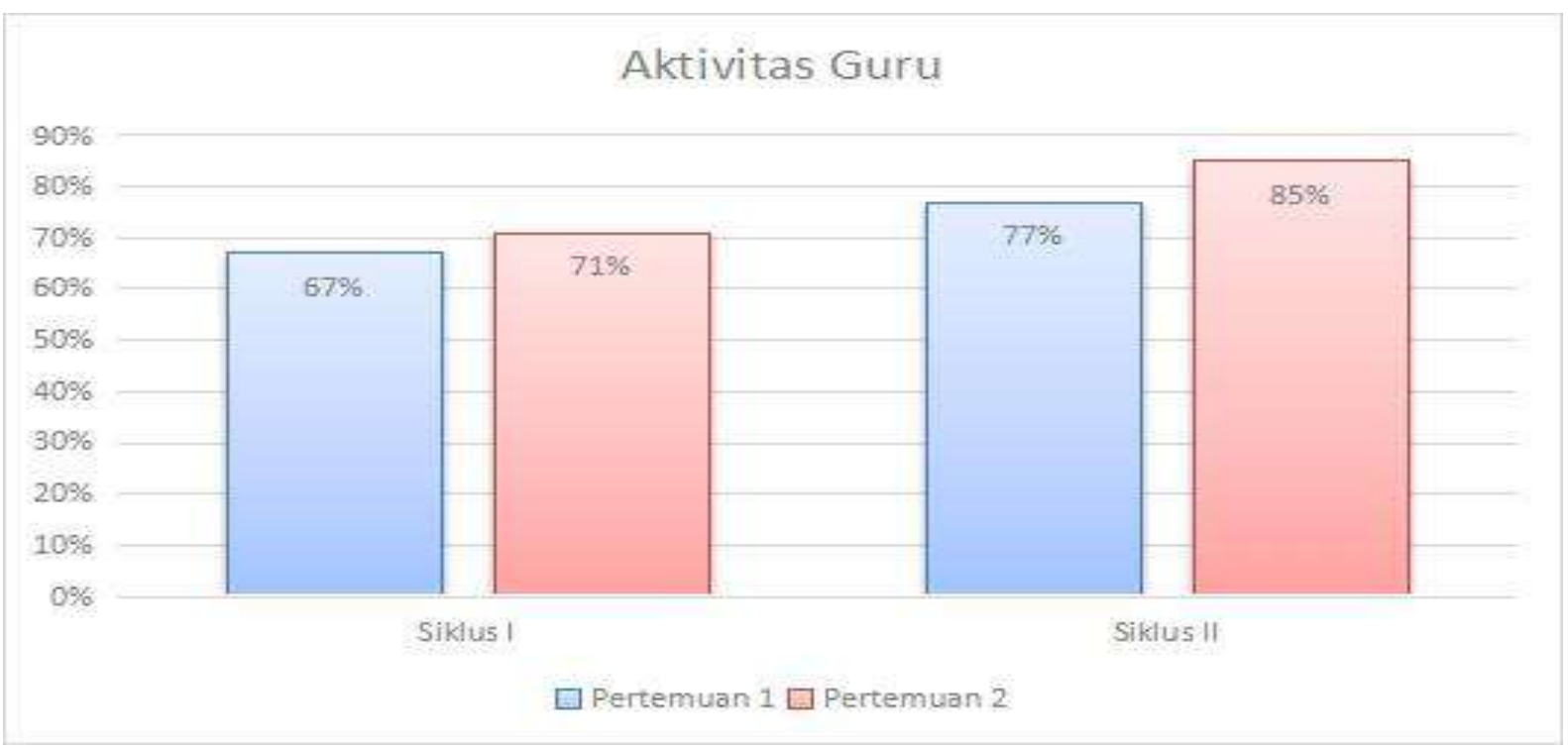

\section{Grafik Aktivitas Guru Siklus I dan Siklus II}

Kecenderungan aktivitas guru dalam melaksanakan pembelajaran mengalami peningkatan pada setiap kali pertemuan, guru lebih baik dalam pelaksanaan tindakan dan sudah terlihat meningkat. Peningkatan aktivitas guru dalam pembelajaran tersebut disebabkan guru sudah dapatmenguasai model yang ditetapkan yaitu model pembelajaran Examples Non Examples, dan juga ada perbaikan pembelajaran melalui refleksi terhadap pembelajaran yang dilakukan.

\section{Aktivitas Siswa}

Aktivitas siswa dalam melaksanakan pembelajaran Bahasa Indonesia pada kompetensi menentukan kosa kata tentang peristiwa siang dan malam. melalui model pembelajaran Examples Non-Examples pada siswakelas I SDN Berangas 1 diketahui bahwa pada Siklus I pertemuan 1 sampai pertemuan 2 mengalami kemajuan yang lebih baik, demikian juga pada siklus II pada pertemuan 1 dan 2 semakin meningkat keterlibatan atau keaktifan siswa dalam kegiatan pembelajaran. Pada siklus I pertemuan 1 mencapai 63,6 \% dan meningkat pada pertemuan 2 menjadi 68,2 \% siswa aktif. Pada siklus II pertemuan 1 mencapai $75 \%$ semakin meningkat pada pertemuan 2 mencapai 81,8 \%. Dengan demikian indikator keberhasilan aktivitas siswa sudah tercapai yakni $\geq 80 \%$ berdasarkan interprestasi keaktifan siswa dengan kategori sangat aktif. Agar lebih jelasnya dapat dilihat dari gambar grafik berikut: 


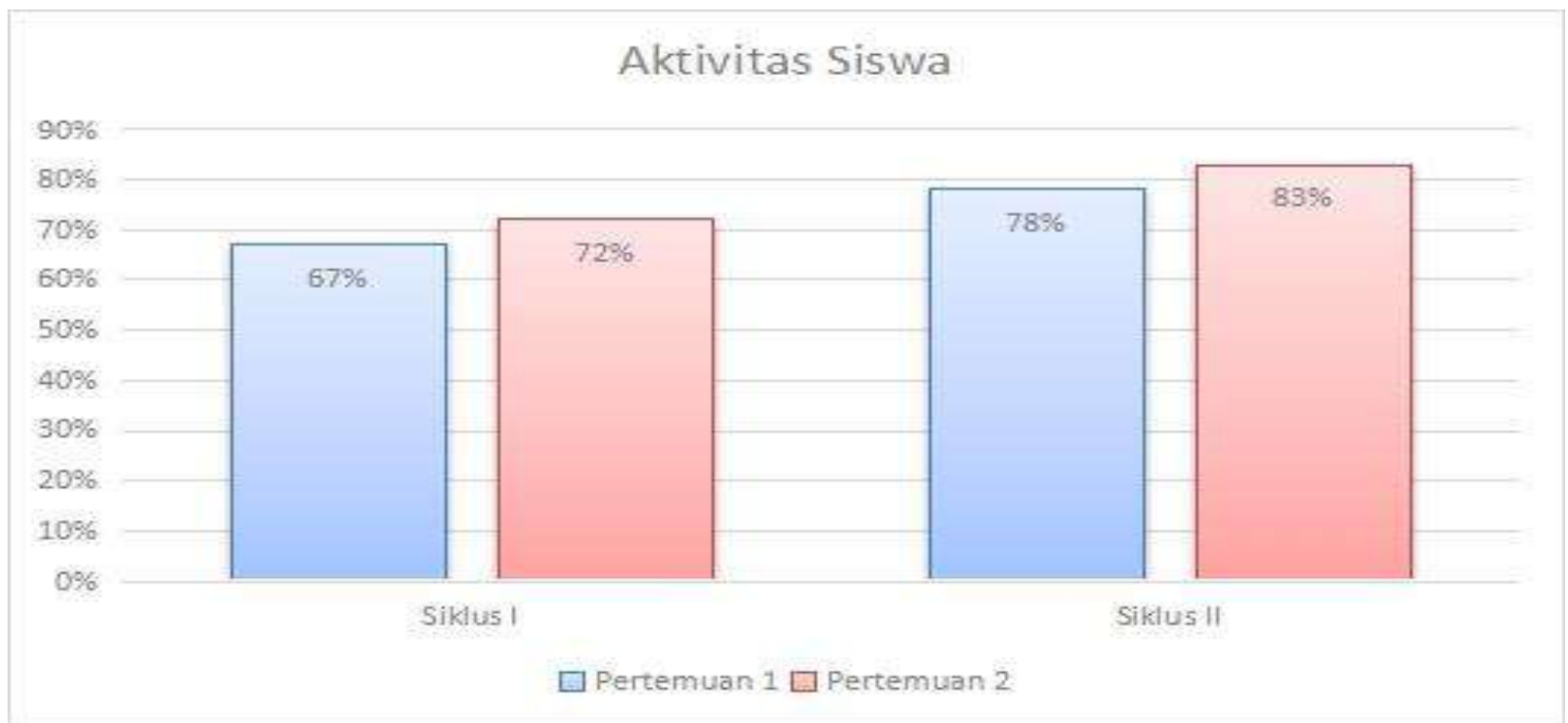

Grafik Aktivitas Siswa Secara Klasikal siklus I dan II

Berdasarkan Grafik hasil observasi siswa dari persentasi aktivitas siswa dalam kegiatan pembelajaran secara keseluruhan mengalami peningkatan dari siklus I ke siklus II pertemuan 1 sampai 2. Hal ini berarti kegiatan pembelajaran dengan melalui model pembelajaran Examples Non-Examples dapat meningkatkan aktivitas siswa dalam kegiatan Pembelajaran. Meningkatnya aktivitas siswa dalam mengikuti kegiatan pembelajaran dengan menggunakan model Examples Non-Examples merupakan suatu hal yang diharapkan dalam tindakan kelas ini. Berdasarkan uraian-uraian di atas peneliti menyimpulkan bahwa kegiatan pembelajaran dengan menggunakan model pembelajaran Example Non-Example dapat meningkatkan aktivitas siswa dalam kegiatan belajar mengajar.

\section{Hasil Belajar Siswa}

Hasil belajar siswa dalam proses pembelajaran Bahasa Indonesia dengan menggunakan model pembelajaran Examples Non Examples di kelas I SDN Berangas 1 pada kompetensi menentukan kosa kata yang berkaitan dengan peristiwa siang dan malam, hasilnya meningkat pada dari siklus I ke siklus II, sehingga mencapai ketuntasan diatas standar ketuntasan yakni $80 \%$ siswa mendapat nilai $\geq 70$ pada penerapan model pembelajaran. Berdasarkan hasil belajar siswa kelas I pada kompetensi menentukan kosa kata yang berkaitan dengan peristiwa siang dan malam menggunakan model Example Non Example melalui media gambar 
diketahui rerata tes formatif pada akhir siklus I pertemuan 1 yaitu 68,6 dan meningkat pada pertemuan 2 menjadi 70,9. Pada siklus II rerata pertemuan 1 yaitu 74,8 meningkat pada pertemuan 2 menjadi 78,1. Temuan ini menunjukkan bahwa hasil belajar siswa telah mencapai ketentuan KKM yang ditetapkan (70). Hasil belajar siswa melalui model examples non examples melalui media gambar telah dapat meningkatkan hasil belajar siswa, dapat dilihat pada grafik berikut :

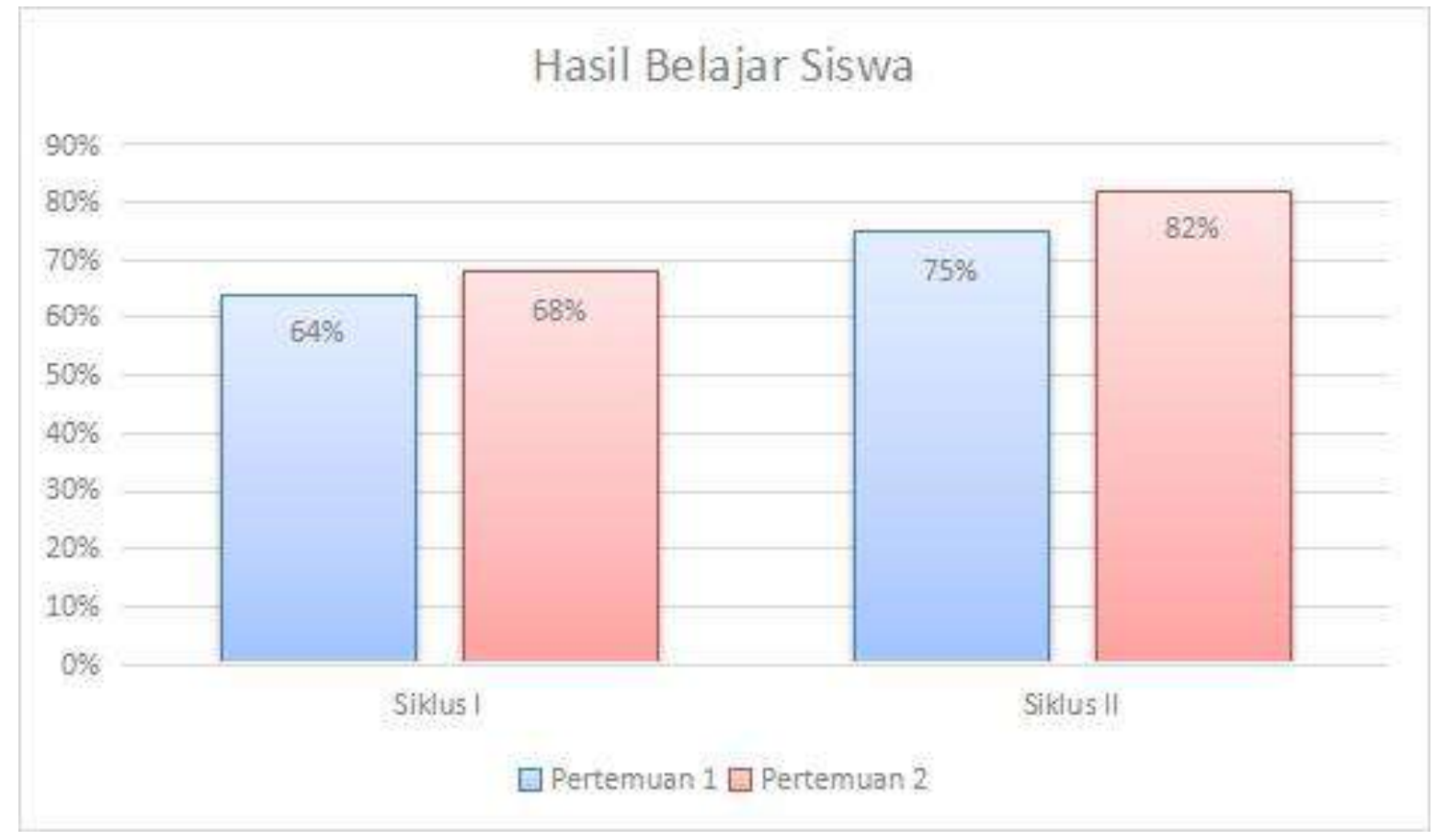

\section{Grafik Hasil BelajarSiswaSiklus I dan Siklus II}

Berdasarkan hasil observasi pada siklus I pertemuan 1 diperoleh persentase ketuntasan klasikal sebesar 66,7\% dan pada pertemuan 2 diperoleh persentase ketuntasan klasikal sebesar 72,2\%. Sedangkan pada siklus II pertemuan 1 diperoleh persentase ketuntasan klasikal sebesar $77,8 \%$ dan pada pertemuan 2 diperoleh persentase ketuntasan klasikal sebesar 83,3\%. Peningkatan hasil belajar yang terjadi pada siklus II pertemuan 2 tidak terlepas dari aktivitas guru dan aktivitas siswa itu sendiri. Aktivitas guru meningkat karena pengelolaan waktu yang efektif dan perbaikan yang dilakukan di setiap pertemuannya sehingga setiap kegiatan pembelajaran yang dilakukan siswa menjadi lebih optimal dan aktivitas siswa pun menjadi meningkat. Dengan adanya peningkatan aktivitas siswa sehingga dapat meningkatkan hasil belajar siswa. Dilihat dari hasil penelitian ini berhasil dan melalui model pembelajaran Examples Non-Examples dapat meningkatkan hasil belajar siswa Kelas I 
Volume 7 Nomor 1, April 2021

SDN Berangas 1 pada matapelajaran Bahasa Indonesia pada kompetensi menentukan kosa kata yang berkaitan dengan peristiwa siang dan malam, dapat diterima.

\section{KESIMPULAN}

Berdasarkan hasil uraian diatas, dapat disimpulkan bahwa:

a. Penggunaan model Example Non-Example pada pembelajaran Bahasa Indonesia Kompetensi menentukan kosa kata tentang peristiwa siang dan malam di kelas I SDN Berangas 1 Kabupaten Barito Kuala mampu meningkatkan keaktifan siswa dalam proses pembelajaran sehingga meningkatkan pemahaman dan penguasaan terhadap materi tersebut. Persentasi aktivitas siswa siklus I mencapai $63,6 \%$ pertemuan 2 mencapai 68,2\% siklus II pertemuan 1 mencapai $75 \%$ dan pertemuan 2 mencapai $81,8 \%$.

b. Aktivitas guru dalam kegiatan pembelajaran menggunakan model Example NonExample pada pembelajaran Bahasa Indonesia Kompetensi menentukan kosa kata tentang peristiwa siang dan malam di kelas I SDN Berangas 1 mampu memperbaiki dan meningkatkan aktivitas guru menjadi lebih baik.Persentasi aktivitas guru Siklus I pertemuan 1 memperoleh 66,7 pertemuan 2 mencapai 70,8 siklus II pertemuan 1 mencapai $77,1 \%$ dan pertemuan 2 mencapai $85,4 \%$.

c. Hasil belajar siswa kelas I SDN berangas 1 pada pembelajaran Bahasa Indonesia Kompetensi menentukan kosa kata tentang peristiwa siang dan malam ketuntasan hasil belajar pada siklus I pertemuan 1 mencapai 66,7\% pertemuan 2 mencapai 72,2\% siklus II pertemuan 1 mencapai 77,8\% dan pertemuan 2 mencapai 85,4\%.

\section{DAFTAR PUSTAKA}

Abimanyu, S.2008, Strategi Pembelajaran, Jakarta: Dirjediktin Depdiknas

Ngalimun dan Rahmat Gazali, 2020, Pola Komunikasi Antar budaya Mahasiswa Asal Thailand Di IAIN Palangka Raya (Thailand Original Culture Communication Patterns In Iain Palangka Raya), Al Ulum Ilmu Sosial dan Humaniora, Vol. 6, No.2, April 2020, hal. 36-50.

Rahmiyanti, Henni Yusda dan Dalimunthe, Sri Mariamah, 2020, Pembelajaran Terpadu Berbasis Karakter Islami Pada Pendidikan Pancasila Dan Kewarganegaraan (PPkn), Al Ulum Ilmu Sosial dan Humaniora, Vol.6, No.2, April 2020, hal. 50-65.

Roestiyah,NK, 2001, Strategi Belajar Mengajar, Jakarta, Renika Cipta

Suprijono, A. 2009. Cooperative Learning Teori dan Aplikasi PAIKEM, Yogyakarta: Pustaka Pelajar.

TIM- FKIP UT. 2014. Pemantapan Kemampuan Profesional. Banten: Universitas Terbuka. 
AL - ULUM ILMU SOSIAL DAN HUMANIORA

ISSN: $2476-9576$

Volume 7 Nomor 1, April 2021 